Erikson, D. \& Webley, D. M. (1953). J. gen. Microbiol. 8, 455-463.

\title{
The Respiration of a Thermophilic Actinomycete, Micromonospora vulgaris
}

\author{
By DAGNY ERIKSON AND D. M. WEBLEY \\ Bacteriology Department, Foresterhill, University of Aberdeen \\ and the Macaulay Institute for Soil Research, Aberdeen
}

SUMMARY: The respiration of Micromonospora vulgaris at $60^{\circ}$ was studied by means of the Warburg technique. Various cultural methods and heat treatments were used to separate the different growth phases of this structurally complex organism. One- to two-day growths bearing aerial mycelium were most active. Spores were inactive. Vegetative mycelium which developed within $24 \mathrm{hr}$. in the Warburg vessels was active, but similar 1-day or older growth harvested from cultures proved to be inactive.

A survey of numerous studies concerned with thermophilic organisms (see Gaughran, 1947) reveals that little attention has been paid to the metabolism of these organisms over the temperature range in which they optimally grow. In his study of certain respiratory enzymes of stenothermophilic bacteria $\left(38-75^{\circ}\right)$, Gaughran (1949) is one of the few who have appreciated the importance of maintaining elevated temperatures throughout an experiment. $\mathrm{He}$ performed his experiments over a range of temperatures whose upper limit was $55^{\circ}$. As far as we are aware, no one has attempted to study the respiration of thermophilic actinomycetes. Erikson (1952) isolated one type of thermophilic actinomycete from composts made from fresh lawn cuttings. All the isolates she made were strains of Micromonospora vulgaris. No thermophilic streptomycetes were found. The cultural studies over the temperature range of growth emphasized the correlation of a well-developed sporogenous aerial mycelium with the high temperature phase; mesophilic strains of Micromonospora sp. do not produce aerial mycelium. In the present work we have attempted to study the respiration of $M$. vulgaris in different mycelial stages at $60^{\circ}$.

\section{METHODS}

Isolation and description of strains of Micromonospora vulgaris

Four strains ( $M, F, D_{3}$ and $B_{4}$ ) isolated from grass composts over successive seasons were used. Their morphological and cultural characteristics are described by Erikson (1953). In addition, a further strain $(\mathrm{H})$ was received from Dr Heller (Ministry of Food, London) who isolated it from canned ham. Apart from a somewhat higher and more consistent heat resistance of the spores, this strain was very like the others.

\section{Technique of growing Micromonospora vulgaris}

Composition of medium. A mixture containing tryptic digest of casein $(5 \%, v / v)$, pea extract $(1 \%, v / v)$ and soluble starch $(1 \%, \mathrm{w} / \mathrm{v})$ (CPS medium as described by Erikson 1952) was used throughout. 
Simultaneous production of top and bottom growth in liquid medium. Large quantities of top and bottom growth were obtained in 50,100 ml. conical and $500 \mathrm{ml}$. round-bottomed flasks after incubation for 1-11 days at $60^{\circ}$. Preheating of vessels, medium and inoculum at $85^{\circ}$ for 5 min., followed by a brief shaking, as previously described (Erikson, 1952), gave the best yields. The method of harvesting top and bottom growth separately is as follows: a short length of glass tubing in the form of a T-piece, having one horizontal arm bent up and the other down, the tail piece being passed just through a rubber bung, is sterilized separately, and fitted into the flask when growth is complete. The flask is then turned upside down, with the result that the non-wetting pellicle of surface growth collects round the walls of the flask while the liquid containing the bottom growth pours through the outlet in the rubber bung directly into sterile centrifuge tubes ready for spinning.

For growth on solid media, cellophan circles, either entire or cut into 4-5 strips, were sterilized in the liquid CPS medium, drained, and then placed over poured plates containing CPS medium solidified with agar; the plates were incubated overnight to test for contamination and then sown with a 2-day surface pellicle from a small liquid culture, the growth being evenly distributed over the cellophan with a bent glass rod. Seven or eight plates were stacked in a sterile metal Petri dish container lined with moistened gauze, and incubated at $60^{\circ}$. The maintenance of a humid atmosphere was essential for the production of a good surface growth with abundant aerial mycelium on the cellophan. On the other hand, the presence of excess liquid actually lying on the cellophan tended to prevent the production of aerial mycelium (see Table 3 ).

\section{Treatment of the material for Warburg experiments}

Young growth (1-2 days) with abundant aerial mycelium proved to be most active in respiration experiments.

Liquid medium; surface growth. The material from CPS medium does not suspend uniformly, and in centrifuging the white aerial growth either floated on the top of the suspending medium and/or adhered to the sides of the tubes. The following procedure was more satisfactory. Medium was removed from below the surface pellicle by means of a sterile pipette; as a result the pellicle floated and adhered to the walls of the vessel. To wash this material, sterile distilled water or $\mathrm{m} / \mathbf{7 5}$ phosphate buffer $(\mathrm{pH} \mathbf{7 \cdot 0}$ ) was added and again removed from below the pellicle. Finally, a known volume of sterile distilled water, CPS medium or $\mathrm{m} / \mathbf{7 5}$ phosphate buffer, was added and the growth quickly washed into the Warburg vessel from the culture vessel. Later it was found more convenient to lift the washed pellicle from the top of the suspending medium and, with a sterile platinum spatula, to transfer it directly into the Warburg vessel containing the suspending medium. The remaining solutions were then added before the vessels were attached to their manometers.

Liquid medium; bottom growth. Even 1-day growth disintegrates after brief shaking or centrifuging. The material therefore was spun for the shortest time compatible with adequate washing of the cells. 
Growth on cellophan strips on solid medium. The strips were curled into the form of a cylinder by using a sterile forceps and the coiled strips bearing the growth put into the Warburg vessels; usually 4-6 coils sufficed. A known volume of sterile distilled water or CPS medium was then added. Usually much of the growth easily detached itself from the strips as they were uncurled and removed aseptically from the vessels. The necessary additions were then made as for liquid cultures. With this procedure there was unavoidable loss of material, as some adhered to the strips as they were removed. Owing to the ease with which vessels became contaminated with thermophilic bacteria, it was necessary before each experiment to sterilize the Warburg vessels, pipettes, solutions, etc., at $\mathbf{2 2 . 5} \mathrm{lb}$./sq.in. for $20 \mathrm{~min}$. At the end of each experiment a nutrient agar plate was streaked from each vessel and then incubated at $60^{\circ}$ overnight or longer to test for thermophilic contaminants.

\section{Comparative viable count of samples of material}

One unit of each type of material prepared for respiration experiments, e.g. one cellophan strip of surface growth, or sample of surface or bottom growth from liquid culture, was tested the same day to determine the approximate number of viable cells. The difficulties of preparing homogeneous suspensions of mixtures of aerial and vegetative mycelium have already been stressed. Yet with constant practice relative values could be obtained by the methods previously described (Erikson, 1952). Certain minor variations of procedure were introduced in the case of surface growth on liquid media; this material was shaken, with or without glass beads, and filtered through glass wool or ground with flattened glass rods before centrifuging. The growth on cellophan strips suspended more readily, especially after storage in sealed tubes for 18-24 hr. at $0^{\circ}$. The most uniform suspensions were obtained with heated growths. (For details of heating, see Tables 2 and 4.). To economize media $0.1 \mathrm{ml}$. of each dilution was added to $1 \mathrm{ml}$. CPS medium $+1 \mathrm{ml} .2 .5 \%$ water agar melted in metal-capped 2 oz. bottles and rolled under a stream of cold water. These roll-tubes were incubated in an inverted position within a moistened sterile tin at $60^{\circ}$ for 2 days. Counts were obtained which compared reasonably well with the customary poured plates. Thus a rough estimate of the relative number of viable cells used in the Warburg vessels was obtained. The average number of viable units/ml./vessel was $2 \times 10^{6}-10 \times 10^{6} \mathrm{from}$ surface growth bearing well-developed aerial mycelium on liquid cultures or cellophan strips. With bottom growth, the numbers of viable units were very variable but always less than from surface growth bearing well-developed aerial mycelium.

Estimation of dry weight of organism used in Warburg experiments. At the end of the experiment, the necks of the Warburg vessels were carefully freed from grease by means of acetone, the $\mathrm{KOH}$ papers and solution removed and the central cup cleaned. The vessel + contents (e.g. organism + buffer, etc.) were dried at $106^{\circ}$ overnight and then weighed. By subtracting from this value the weight of the vessel + buffer etc., the dry weight of the organism was estimated. Although not an entirely satisfactory method, this proved the only practical way of estimating the dry weight of organism used. 


\section{Running the Warburg apparatus at $60^{\circ}$}

The apparatus we used has a large deep tank and is fitted with an automatic setting arrangement which allows the heating to be started in the early hours of the morning. It took about $5 \mathrm{hr}$. to reach $60^{\circ}$. It was occasionally necessary during the experiment to add water, previously heated to the temperature of the bath, to make up for evaporation; this was done between readings. Variations in temperature during an experiment could not be detected on a thermometer graduated to $0 \cdot 5^{\circ}$. There was however a slight rise or fall in the manometer fluid, amounting at most to $4-5 \mathrm{~mm}$. divisions on the manometer scale. This was due to the interval between the cutting-out of the heating elements and the subsequent attainment of equilibrium, and did not affect the positive results indicated in the tables; small figures which might fall within this range are there noted. It was necessary to use a special sealing grease for the manometer ends and vessel stoppers; Apiezon T Grease (Shell Chemicals Ltd.) was very satisfactory for this purpose, and was easily removed by acetone at the end of experiments. The manometer taps were unaffected by the temperature and no special tap grease was required for them. Occasionally (particularly when the experiments were run for more than $3 \mathrm{hr}$.) a small column of water (due to condensation of droplets) formed above or below the bend in the manometer arm. This column was usually easy to dislodge by raising and lowering the manometer fluid in the manometer limbs as is done when removing air bubbles in the manometer fluid. Equilibrium time was usually $15 \mathrm{~min}$. and the rate of shaking $90-100$ oscillations/min. The volume in each vessel was $2.5 \mathrm{ml}$. with $0.2 \mathrm{ml}$. of $5 \%(\mathrm{w} / \mathrm{v}) \mathrm{KOH}$ in the centre cup. $K_{\mathrm{O}_{2}}$ was calculated for $60^{\circ}$.

\section{RESULTS}

From Table 1 it will be seen that there was a marked oxygen uptake in the presence of CPS medium; control vessels containing sterile CPS medium consistently gave no oxygen uptake. The endogenous respiration in presence of distilled water or phosphate buffer was very small. At the end of experiments some of the organism had usually accumulated on the wall of the vessels while the remainder was not suspended uniformly throughout the liquid. Material adhering to the vessel wall is, however, repeatedly washed during the shaking of the manometers. The shaking broke up the material to a certain extent, but this did not appear to interfere with ability to take up oxygen. This is borne out by the later entries in Table 1. Attempts were made to disperse the growth in the vessels by the addition of non-toxic wetting agents (e.g. Tween 80), but without success. Erikson (1952) also failed to make suspensions of surface growth in this way. Determinations of $\mathrm{pH}$ values showed practically no change during the period of the experiment $(3 \mathrm{hr}$.).

The procedure of heating for $15 \mathrm{~min}$. at $85^{\circ}$ results in destruction of vegetative mycelium while a considerable proportion of the spores remain viable (Erikson, 1952). Examples of the way in which the oxygen uptake is influenced by this treatment are given in Table 2. A substantial decrease in 


\section{Table 1. $\mathrm{O}_{2}$ uptake of Micromonospora vulgaris at $60^{\circ}$ in presence and absence of CPS medium}

$M$. vulgaris (strain F) grown for 2 days at $60^{\circ}$ on cellophan strips overlying solid CPS medium. Strips either put directly into vessels followed by $2.5 \mathrm{ml}$. distilled water or CPS medium or $\mathrm{M} / 75$ phosphate buffer $(\mathrm{pH} 7 \cdot 0)$ and then removed; or shaken beforehand with a few sterile glass beads in presence of CPS medium or distilled water in wide sterile tubes. Strips removed from tubes and contents pipetted into vessels. Duration of experiment $3 \mathrm{hr}$.

$\begin{array}{ccc} & \mathrm{O}_{2} \text { uptake } & \text { Dry weight } \\ \begin{array}{c}\text { Suspension } \\ \text { medium }\end{array} & (\mu \mathrm{l} . / \mathrm{hr} . ; & \text { of material } \\ \text { average }) & (\mathrm{mg} .)\end{array}$

Undisturbed organisms

$\begin{array}{lcc}\text { CPS } & \mathbf{2 6} \cdot 2 & \mathbf{1} \cdot 3 \\ \text { CPS } & \mathbf{9 5} \cdot 7 & \mathbf{3 \cdot 2} \\ \text { Dist. water } & 2 \cdot 4 * & \mathbf{5} \cdot \mathbf{5} \\ \text { Dist. water } & 6 \cdot 4 & 6 \cdot 1 \\ \text { M/75 phosphate buffer } & \mathbf{9 \cdot 3} & \mathbf{6 \cdot 4}\end{array}$

Organisms shaken with beads

$\begin{array}{lrc}\text { Dist. water } & 11 \cdot 0 & \text { nt. } \\ \text { Dist. water } & 9 \cdot 8 & \text { nt. } \\ \text { CPS } & \mathbf{3 7 2 \cdot 4} & \text { nt. } \\ \text { CPS } & \mathbf{4 6 3 \cdot 0} & \text { nt. }\end{array}$

\footnotetext{
* Total $\mathrm{O}_{2}$ uptake within experimental error (see Methods). nt. = not tested.
}

\section{Table 2. Differences in oxygen uptake at $60^{\circ}$ of spores and mycelial growth of Micromonospora vulgaris}

$M$. vulgaris (strains $\mathrm{D}_{3}$ and $\mathrm{M}$ ) grown on liquid CPS medium for 1 day at $60^{\circ}$. Growth then (i) washed once with $2.5 \mathrm{ml}$. distilled water before placing in Warburg vessels or (ii) heated in distilled water at $85^{\circ}$ for $15 \mathrm{~min}$. before placing in the vessels; $0.5 \mathrm{ml} . \mathrm{M} / 15$ phosphate buffer $+1.0 \mathrm{ml}$. CPS medium added with distilled water to give a final volume of $2.5 \mathrm{ml}$. Strain M also grown for 2 days at $60^{\circ}$ on cellophan strips overlying solidified CPS medium. Half of the strips were removed, put into sealed tubes and heated submerged in a water bath at $85^{\circ}$ for $15 \mathrm{~min}$. (details, see Erikson, 1952). Strips then put into Warburg vessels containing $1 \mathrm{ml}$. distilled water. After removal of strips $0.5 \mathrm{ml} . \mathrm{M} / 15$ phosphate buffer $+1.0 \mathrm{ml}$. CPS medium and distilled water added to give a final volume of $2.5 \mathrm{ml}$. Exps. 1-4, strain $D_{3}$ surface growth on liquid medium; Exps. 5-8, strain $M$, ditto; Exps. 9 and 10, strain $M$, grown on cellophan.

\begin{tabular}{|c|c|c|c|c|c|}
\hline Exp. & $\begin{array}{l}\text { Treatment } \\
\text { of organism }\end{array}$ & $\begin{array}{c}\mathrm{O}_{2} \text { uptake } \\
(\mu \mathrm{l} . / \mathrm{hr} . ; \\
\text { average })\end{array}$ & $\begin{array}{c}\text { Duration of } \\
\text { experiment } \\
\text { (hr.) }\end{array}$ & $\begin{array}{c}\text { Dry weight } \\
\text { of material } \\
(\mathrm{mg} .)\end{array}$ & $\begin{array}{c}\text { Comparative viable } \\
\text { count/ml./vessel at } \\
\text { beginning of experiment }\end{array}$ \\
\hline 1 & Unheated & 63.0 & 2 & $2 \cdot 4$ & $1,750,000$ \\
\hline 2 & Unheated & $44 \cdot 2$ & 2 & $2 \cdot 6$ & nt. \\
\hline 3 & Heated & $8 \cdot 4$ & 2 & $2 \cdot 1$ & 500,000 \\
\hline 4 & Heated & 4.9 & 2 & $2 \cdot 5$ & nt. \\
\hline 5 & Unheated & $85 \cdot 3$ & 3 & $1 \cdot 3$ & $7,900,000$ \\
\hline 6 & Unheated & $61 \cdot 1$ & 3 & $0 \cdot 7$ & nt. \\
\hline 7 & Heated & 0 & 3 & $0 \cdot 8$ & 850,000 \\
\hline 8 & Heated & 0 & 3 & $1 \cdot 3$ & nt. \\
\hline 9 & Unheated & $207 \cdot 9$ & $1 \frac{1}{2}$ & $3 \cdot 6$ & $5,000,000$ \\
\hline 10 & Heated & $13 \cdot 5$ & $1 \frac{1}{2}$ & $3 \cdot 3$ & 700,000 \\
\hline
\end{tabular}


the oxygen uptake followed heating at $85^{\circ}$ for $15 \mathrm{~min}$. in all instances. This indicates that the spores have a very low oxygen uptake. All the plates streaked from the vessels containing heated material showed good growth after incubation overnight at $60^{\circ}$, even where no oxygen uptake was observed in $3 \mathrm{hr}$. (Table 2).

It was repeatedly observed that the more abundant the white aerial mycelium was the more active oxygen uptake this material showed. Experiments with different types of mycelial growth prepared as described in the section on methods emphasize these differences, as can be seen in Table 3 .

Table 3. $\mathrm{O}_{2}$ uptake at $60^{\circ}$ shown by different types of mycelial growth of Micromonospora vulgaris

$M$. vulgaris (strains $M, B_{4}$ and $\left.D_{3}\right)$. Surface and bottom growth $\left(B_{4}\right.$ and $\left.D_{3}\right)$ from liquid culture after pre-heating at $85^{\circ}$ for $5 \mathrm{~min}$. followed by incubation at $60^{\circ}$ for $1-2$ days; surface growth removed, and bottom growth spun down. After washing, growth transferred to vessels $+0.5 \mathrm{ml}$. $\mathrm{m} / 15$ phosphate buffer $+1.0 \mathrm{ml}$. CPS medium $+1.0 \mathrm{ml}$. distilled water.

Strain M grown on cellophan strips overlying solidified CPS medium for 2 days at $60^{\circ}$. Strips put into Warburg vessels containing $1 \mathrm{ml}$. distilled water. After removal of strips, $0.5 \mathrm{ml}$. $\mathrm{M} / 15$ phosphate buffer $(\mathrm{pH} 7 \cdot 0)+1 \mathrm{ml}$. CPS medium added.

\begin{tabular}{|c|c|c|c|c|c|c|}
\hline Strain & Type of growth & $\begin{array}{c}\text { Age } \\
\text { (days) }\end{array}$ & $\begin{array}{c}\mu \mathrm{l} . \mathrm{O}_{2} \\
\text { uptake } \\
(\mu \mathrm{l} . / \mathrm{hr} . \\
\text { average })\end{array}$ & $\begin{array}{l}\text { Duration } \\
\text { of } \\
\text { experiment } \\
\text { (hr.) }\end{array}$ & $\begin{array}{l}\text { Dry wt. } \\
\text { of } \\
\text { material } \\
\text { (mg.) }\end{array}$ & $\begin{array}{l}\text { Comparative viable } \\
\text { count } / \mathrm{ml} \text {./vessel } \\
\text { at beginning of } \\
\text { experiment }\end{array}$ \\
\hline $\mathbf{D}_{3}$ & $\begin{array}{l}\text { Surface; on liquid } \\
\text { medium }\end{array}$ & 1 & $63 \cdot 0$ & 3 & $2 \cdot 4$ & $1,750,000$ \\
\hline $\mathbf{D}_{3}$ & $\begin{array}{l}\text { Bottom growth from } \\
\text { above }\end{array}$ & 1 & 0 & 3 & $4 \cdot 9$ & 4,000 \\
\hline M & $\begin{array}{l}\text { Surface on cellophan; } \\
\text { well-developed aerial } \\
\text { mycelium }\end{array}$ & 2 & $541 \cdot 2$ & $1 \frac{1}{2}$ & $8 \cdot 1$ & $10,000,000$ \\
\hline M & $\begin{array}{l}\text { Surface on cellophan; } \\
\text { poor development } \\
\text { of aerial mycelium* }\end{array}$ & 2 & $11 \cdot 0$ & $1 \frac{1}{2}$ & $2 \cdot 1$ & 320,000 \\
\hline $\mathbf{B}_{4}$ & $\begin{array}{l}\text { Surface on liquid } \\
\text { medium }\end{array}$ & 2 & $24 \cdot 8$ & $1 \frac{1}{2}$ & nt. & $8,250,000$ \\
\hline $\mathbf{B}_{4}$ & $\begin{array}{l}\text { Bottom growth from } \\
\text { above }\end{array}$ & 2 & 0 & $1 \frac{1}{2}$ & nt. & 145,000 \\
\hline
\end{tabular}

* The specimen of growth on cellophan which yielded poor aerial mycelium was obtained following excessive moisture on the plates (see Methods). nt. $=$ not tested.

It is quite clear from these experiments that a surface growth which bears abundant aerial mycelium is by far the most active of the various kinds of growth in taking up oxygen under our experimental conditions. From the results of Table 2 we know that only a very small percentage of this oxygen uptake can be due to the spores themselves. This leads to the conclusion that it is the aerial mycelium which is most active. Even here there are differences corresponding to the vigour of the individual culture on specific occasions. It is also clear that dry weight is inadequate as a quantitative measure for the respiration of this type of material, it being impossible to determine for any given sample the relative amounts of spores, aerial and non-aerial mycelium. 
When young surface growth of $\boldsymbol{M}$. vulgaris is respiring in the presence of CPS medium in the Warburg vessels, the oxygen uptake consistently increases throughout the course of the experiment. Similarly, we found (Table 4) that old surface growth or young surface growth which had been heated, although showing no immediate uptake of oxygen, did after a lag period begin to respire, and this rate of respiration also increased with time.

The length of the lag period varied according to age, treatment and quantity of material used. Thus in the first four entries in Table 4 the variable lag was also an expression of part of the survivor curve in a heat-test experiment. After $5 \mathrm{~min}$. at $100^{\circ}$ it took 3-4 hr. for sufficient spores to germinate and register a measurable amount of oxygen uptake. After $10 \mathrm{~min}$. at $100^{\circ}$ no oxygen uptake was evident within $7 \frac{3}{4} \mathrm{hr}$. (first day of the experiment), although naturally many spores must have germinated within the period 7-24 hr. in order to give the large oxygen uptake registered the following morning. The much less drastic degree of heating ( $85^{\circ}$ for $15 \mathrm{~min}$.) used as a method of separating spores from mycelium had little damaging effect upon the spores, but in the fifth and sixth entries it will be seen that it took 3-4 hr. for the growth from newly germinated spores to respire at a rate comparable with that of the unheated surface mycelium ( 2 days old). Older surface mycelial growth $(4,6$ and 11 days) seemed very inactive, for the figures shown in Exps. 14, 17 and 9 could be explained as the respiratory rates of the new growth.

Bottom growth from cultures 1, 2, 4 or 11 days old, when transferred to the vessels never showed any oxygen uptake during a $7 \frac{1}{2} \mathrm{hr}$. period of observation. When observation was continued for $24 \mathrm{hr}$., only one of the five (Exp. 16) showed some oxygen uptake. Where positive values for oxygen uptake are given only after a considerable lag, they represent respiration of young (less than $24 \mathrm{hr}$.) vegetative mycelium which has grown in the Warburg vessels. In normal growth experiments, spores of $\boldsymbol{M}$. vulgaris usually germinate within 1-2 hr. in CPS medium at $60^{\circ}$.

\section{DISCUSSION}

A consideration of the results hinges round two points: the validity of the values given by our technique as a measure of respiration at $60^{\circ}$, and the significance of the differences in oxygen uptake observed as between spores, aerial and non-aerial mycelium. In view of the low endogenous respiration of $\boldsymbol{M}$. vulgaris (Table 1 ), the consistently negative values given by uninoculated CPS medium, and the very high oxygen uptake shown in all positive results, there can be little doubt that the method gives a true picture of the respiration of the organism. We wish to emphasize, however, that our results should be looked upon in a qualitative light. The conventional methods for the study of oxygen uptake by bacteria (e.g. use of homogeneous suspensions) are not suitable for this type of highly organized material. In particular, the expression of quantity of actively respiring material by dry weight lacks precise meaning (e.g. see Table 4, Exps. 17, 18 and 19). It was therefore necessary to depend on ability to obtain different types of growth by suitable cultural 
462

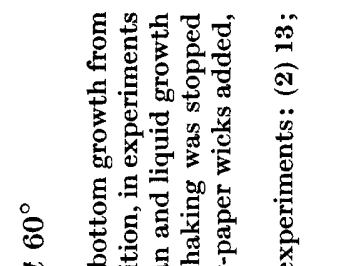

उ

约

政要

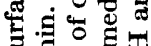

की

它放记

苍品富忽

.

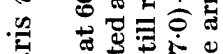

预

5 ง $\Xi$

एँ

응

造要

政

웡

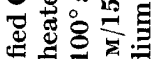

此

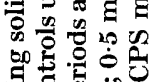

象造苍

跑

वें

फ़

政尊

式语

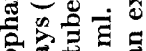

-

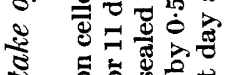

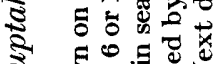

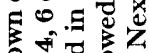

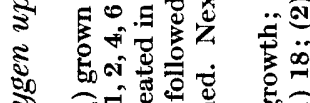

लिख्य

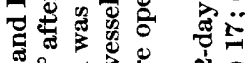

म

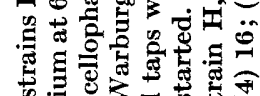

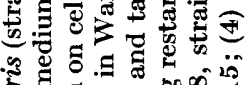

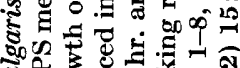

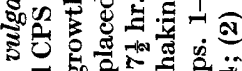

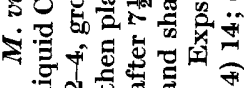

D. Erikson and D. M. Webley

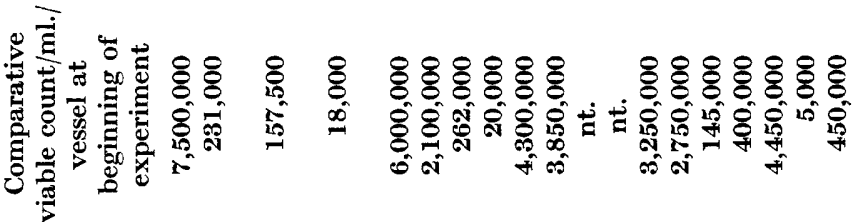

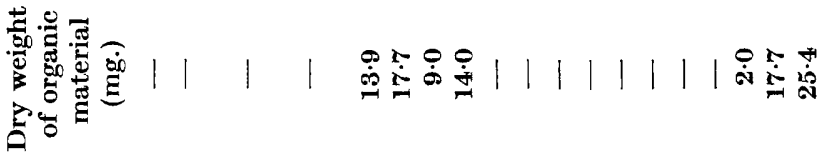

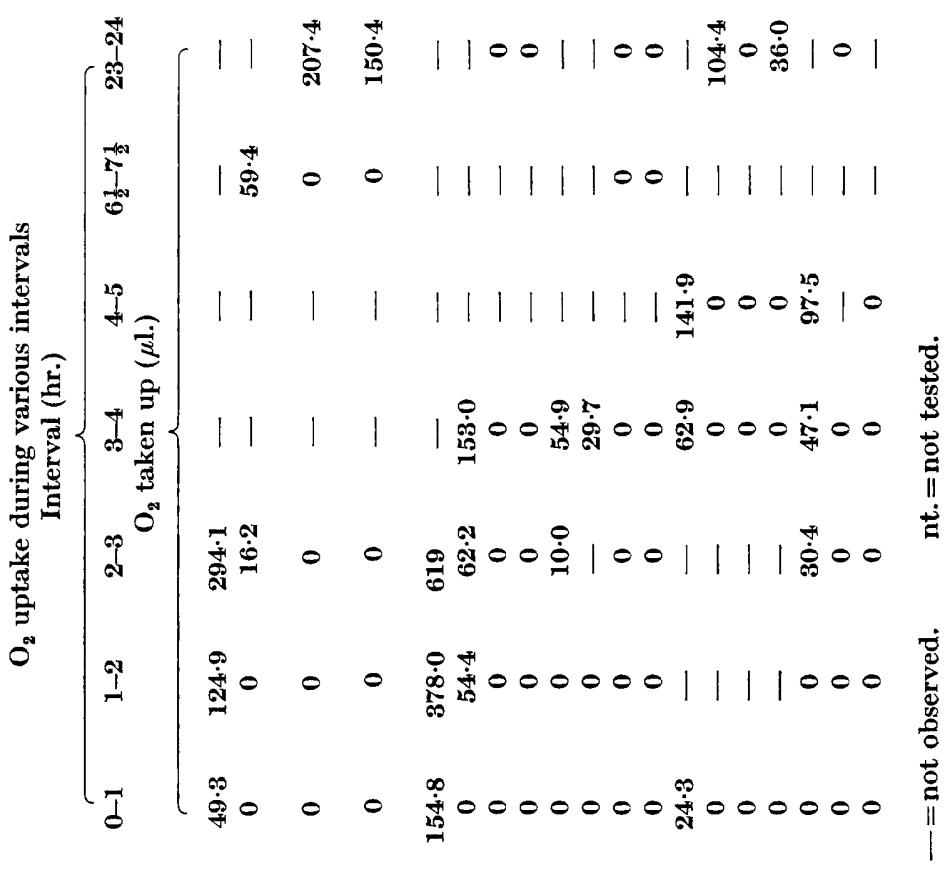

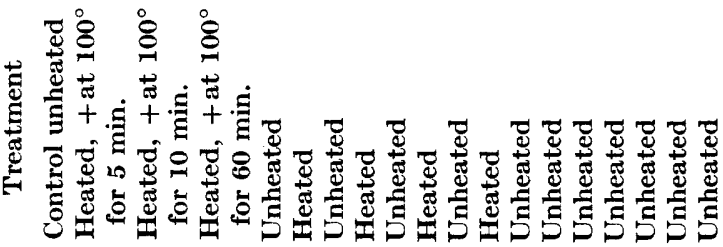
若

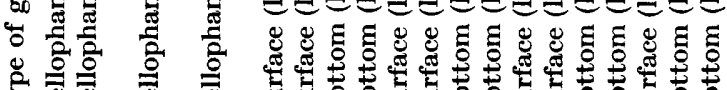

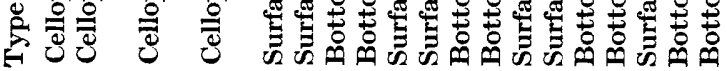
离ー 
methods and also on heat treatment as a means of separating vegetative organism from spores. The customary procedure of heating at $85^{\circ}$ for $15 \mathrm{~min}$. to destroy vegetative mycelium resulted in a clear and immediate decrease in the oxygen uptake (see Table 2). For the quantities of material used in these experiments, the method is not sensitive enough to measure oxygen uptake by resting spores. Similarly, vegetative mycelium harvested mainly from liquid cultures registered no oxygen uptake even when 1 day old (see Tables 3 and 4). It is probable here that there has been a very considerable drop in respiratory activity after harvesting; the filaments are very fragile and break easily (see Erikson, 1953). Here again the method possibly fails in sensitivity since growth from newly germinated spores which develop in the Warburg vessels themselves was active (see Table 4).

The morphological development so far outlined is analogous to that of thermophilic eubactria. M. vulgaris, however, under optimal conditions develops a secondary aerial mycelium of considerable complexity. Table 3 illustrates the differences in oxygen uptake shown by simple vegetative growth and preparations of the organism which have attained their full development. The respiratory activity of this aerial mycelium is of short duration, and diminishes rapidly after 1-2 days, according to experimental conditions.

The senior author (D.E.), who is a member of the scientifie staff of the Agricultural Research Council, wishes to thank Prof. J. Cruickshank, for the hospitality of his Department. Grateful acknowledgement is made to the Agricultural Research Council for an expenses grant. We wish to thank Miss Irene Taylor and Miss Mildred Mackay for technical assistance, and Dr G. K. Fraser for his interest throughout the work.

\section{REFERENCES}

ErIKson, D. (1952). Temperature growth relationships of a thermophilic actinomycete Micromonospora vulgaris. J. gen. Microbiol. 6, 286.

Erikson, D. (1953). The reproductive pattern of M.vulgaris. J.gen. Microbiol. 8, 449.

Gaughran, E. R. L. (1947). The thermophilic micro-organisms. Bact. Rev. 11, 189.

Gaughran, E. R. L. (1949). Temperature activation of certain respiratory enzymes of stenothermophilic bacteria. J. gen. Physiol. 32, 313.

(Received 5 December 1952) 